\title{
Ionospheric storm forecasting technique by artificial neural network
}

\author{
Ljiljana R. Cander $\left({ }^{1}\right)$, Milan M. Milosavljević $\left({ }^{2}\right)$ and Saša Tomasević $\left({ }^{2}\right)$ \\ $\left(^{1}\right)$ Rutherford Appleton Laboratory, Chilton, Didcot, Oxon, U.K. \\ $\left(^{2}\right)$ Faculty of Electrical Engineering, University of Belgrade, Belgrade, Serbia and Montenegro
}

\begin{abstract}
In this work we further refine and improve the neural network based ionospheric characteristic's foF 2 predictor, which is actually a neural network autoregressive model with additional input signals (NNARX). Our analysis is focused on choice of X parts of NNARX model in order to capture middle and long term dependencies. Daily distribution of prediction error suggests need for structural changes of the neural network model, as well as adaptation of running average lengths used for determination of $\mathrm{X}$ inputs. Generalisation properties of proposed neural predictor are improved by carefully designed pruning procedure with additional regularisation term in criterion function. Some results from the NNARX model are presented to illustrate the feasibility of using such a model as ionospheric storm forecasting technique.
\end{abstract}

Key words prediction and forecasting - neural networks - ionospheric storms modelling - space weather

\section{Introduction}

There are a number of methods available for prediction and forecasting characteristics relevant to ionospheric telecommunication applications (Kutiev et al., 1999; Fuller-Rowell et al., 2000; Muhtarov et al., 2001; Muhtarov et al., 2002; Cander, 2003 and references therein). The user usually requires ionospheric forecasting that are near real time for radar and surveillance applications and over 1-24 h ahead for pointto-point and mobile communications (Cander, 1998). The neural network non-linear techniques are based on finding more complex correlation over a greater number of steps. Successful

Mailing address: Dr. Ljiljana R. Cander, Rutherford Appleton Laboratory, Chilton, Didcot, Oxon OX11 0QX, U.K.; e-mail: 1.cander@rl.ac.uk attempts to build different artificial neural networks models for the critical frequency of the ionospheric $F_{2}$ layer, $f o F 2$, prediction and forecasting have already been made at monthly (Lamming and Cander, 1998, 1999) and daily time scales (Williscroft and Poole, 1996; Altinay et al., 1997; Wintoft and Cander, 2000a,b; Francis et al., 2001).

The aim of the paper is to provide a concise summary of the application and development of non-linear neural network techniques to improve ionospheric storm forecasting capabilities. It is shown that the NNARX - neural network based autoregressive model with additional inputs (X) can provide forecasting of the hourly variation of foF 2 from $1 \mathrm{~h}$ ahead, as the shortest time scale over which the ionosphere can be predicted forwards extremely well.

\section{2. foF2 data source}

The data used for $f_{o} F 2$ forecasting $1 \mathrm{~h}$ ahead are values taken from the Rutherford Appleton Laboratory CD-ROM produced within COST 251 project (http://www-cost251.rcru.rl.ac.uk/) 
Table I. List of European ionospheric stations with their URSI codes and geographical coordinates.

\begin{tabular}{cccc}
\hline $\begin{array}{c}\text { Ionospheric } \\
\text { stations }\end{array}$ & $\begin{array}{c}\text { URSI } \\
\text { codes }\end{array}$ & $\begin{array}{c}\text { Latitude } \\
(\mathrm{N})\end{array}$ & $\begin{array}{c}\text { Longitude } \\
(\mathrm{E})\end{array}$ \\
\hline Rome & RO041 & 41.9 & 12.5 \\
Sofia & SQ143 & 42.7 & 23.4 \\
Grocka & BE145 & 44.8 & 20.5 \\
Poitiers & PT046 & 46.6 & 0.3 \\
Slough & SL051 & 51.5 & -0.6 \\
Julisruh & JR055 & 54.6 & 13.4 \\
Moscow & MO155 & 55.5 & 37.3 \\
Uppsala & UP158 & 59.8 & 17.6 \\
\hline
\end{tabular}

for a few European stations listed in table I. The forecast periods were chosen to be February 1986, September and December 1990 representing low and high solar activity as well as geomagnetically disturbed and quiet periods. Table II gives the details concerning the solar-terrestrial conditions during selected periods.

The NNARX model was trained using hourly foF 2 values from 01 January to 31 December during years of 1986 and 1990 excluding months for which forecasting has been made: February in case of 1986, September in case I on 1990 and December in case II on 1990.

In table II $R_{i}$ is the international relative sunspot number and $A_{p}$ is an averaged planetary geomagnetic index based on data from a set of specific geomagnetic observatories. It serves to classified the storms as follows:

1) Minor geomagnetic storm: a storm for which the $A_{p}$ index was greater than 29 and less than 50 .

2) Major geomagnetic storm: a storm for which the $A_{p}$ index was greater than 49 and less than 100 .

3) Severe geomagnetic storm: a storm for which the $A_{p}$ index was 100 or more.

The $D_{s t}$ index is an index of geomagnetic activity derived from a network of near-equatorial geomagnetic observatories that measures the intensity of the globally symmetrical equatorial electrojet (the «ring current»). Peaks $D_{s t}$ values are between - 20 and 20 nT during quiet geomagnetic condition and decrease to below -100 nT during highly disturbed periods. In the case of severe geomagnetic storms, $D_{s t}$ values are below - $250 \mathrm{nT}$.

\section{NNARX model and training procedure}

NNARX - neural network based autoregressive model with additional inputs $(\mathrm{X})$ is one possible approach that use the hybrid timedelay multi-layer percepton neural network with only critical frequency of the ionospheric $F_{2}$ layer as input parameter to produce one output $f o F 2$ value at hour $t+1$. Inputs $(\mathrm{X})$ include $f o F 2$ value at time $t$, seven days mean $M f o F 2$ values and

Table II. Solar-terrestrial conditions during selected periods used in this study.

\begin{tabular}{lccc}
\hline \hline \multicolumn{1}{c}{ Months } & $\begin{array}{c}\text { Days with storm } \\
\text { commencement }\end{array}$ & $\begin{array}{c}\text { Min } D_{s t} \\
\text { geomagnetic index }\end{array}$ & $\begin{array}{c}\text { Max } A_{p} \\
\text { geomagnetic index }\end{array}$ \\
\hline $\begin{array}{l}\text { February 1986 with } \\
\text { monthly mean sunspot } \\
\text { number } R_{i}=23.2\end{array}$ & 06 at 1312 UT & -307 nT on 9 February & 208 on 8 February \\
\hline $\begin{array}{l}\text { September 1990 with } \\
\text { monthly mean sunspot } \\
\text { number } R_{i}=125.2\end{array}$ & 01 at 1024 UT & -48 nT on 1 September & 26 on 1 September \\
\hline $\begin{array}{l}\text { December 1990 with } \\
\text { monthly mean sunspot } \\
\text { number } R_{i}=129.7\end{array}$ & 21 at 1724 UT & -47 on 24 December & 15 on 24 December \\
\hline
\end{tabular}


appropriate differences $\triangle M f o F 2$ at particularly selected hours $(t, t-1, t-23, t-47)$ as well $M f o F 2$ at forecast time $(t+1)$ calculated using only the learning set of data to generate the background daily variations of foF 2 . Detailed description of this type of the neural network as far as its architecture, first and second hidden layers, learning and test data sets are concerned can be found in Cander et al. (1998a,b).

The NNARX is trained using cost function with a weight-decay term (Bishop, 2000). Our experimental experience showed that only the weight-decay scheme is not enaugh to overcome the overfitting problem. Namely, it would have been possible to increase the weight-decay parameters, which have also been tried, but when increasing the weight-decay parameters the quadratic error term in the cost-function increase. This is an undesirable effect, as it is this part of the cost function that is especially interesting and should be minimized as much as possible. Therefore a pruning scheme is used to remove superfluous parameters from the network architecture (Le Cun et al., 1990). The so called Akaike's Final Prediction Error (FPE) estimate of the test error is used to point out which structure is the optimal (Akaike, 1969). Additionally, we then tried to retrain the optimal network structure to see if it is possible to overcome the problem of overtraining when optimal network structure already has been found. The experimental results showed that retrained optimal networks possess very good generalyzation properties. All results presented in sequal are obtained by the such retrained optimal networks.

\section{NNARX model results}

Accuracy of prediction, clearly stating range and scope of test conditions, i.e., show the breakdown between training and test data, indicate any comparisons made with other or reference models such as persistence for example. For comparative purposes the accuracy of the NNARX model is quoted in terms of both the Root Mean Square (RMS) error and the Normalised RMS Error defined as

$$
\mathrm{NRMSE}=\sqrt{\left(\left(\sum_{i}\left(x_{i}-y_{i}\right)^{2} / n\right) / \sigma^{2}\right)}
$$

where $x$ are the actual foF 2 values, $y$ are the predicted $f_{o} F 2$ values, $n=\Sigma_{i}$ is the total number of comparisons between actual and predicted values and $\sigma$ is the standard deviation of the actual values from the mean value given by

$$
\sigma^{2}=\frac{\sum_{i}\left(\bar{X}-x_{i}\right)^{2}}{n} .
$$

The predictive accuracy of the NNARX model is summarised in the tables III and IV. In these tables all errors are quoted with respect to the one step ahead NNARX predictive model, for the entire test set in each instance. The persistence model results are included in table III as an effective reference in each instance. It can be seen in these RMS and NRMS errors

\begin{tabular}{|c|c|c|c|c|}
\hline \multirow{2}{*}{$\begin{array}{c}\text { Ionospheric stations } \\
\text { February } 1986\end{array}$} & \multicolumn{2}{|c|}{ RMS error $(\mathrm{MHz})$} & \multicolumn{2}{|c|}{ NRMSE } \\
\hline & Persistence & NNARX model & Persistence & NNARX model \\
\hline RO041 & 0.6482 & 0.4456 & 0.4740 & 0.3258 \\
\hline SQ143 & 0.6178 & 0.4460 & 0.4469 & 0.3226 \\
\hline РT046 & 0.8097 & 0.4745 & 0.3568 & 0.2091 \\
\hline SL051 & 0.7213 & 0.5258 & 0.5285 & 0.3853 \\
\hline MO155 & 0.6121 & 0.3778 & 0.4288 & 0.2647 \\
\hline
\end{tabular}

Table III. RMS and NRMS errors at different stations for February 1986. 
Table IV. RMS errors at different stations for September and December 1990.

\begin{tabular}{ccc}
\hline \hline $\begin{array}{c}\text { Ionospheric } \\
\text { stations }\end{array}$ & $\begin{array}{c}\text { RMS error (MHz) } \\
\text { NNARX model } \\
\text { September 1990 } \\
\text { case I }\end{array}$ & $\begin{array}{c}\text { RMS error (MHz) } \\
\text { NNARX model } \\
\text { December 1990 } \\
\text { case II }\end{array}$ \\
\hline RO041 & 0.49 & 0.57 \\
SQ143 & 0.96 & 0.88 \\
PT046 & 0.45 & 0.60 \\
SL051 & 0.44 & 0.58 \\
UP158 & 0.44 & 0.60 \\
\hline
\end{tabular}

values that there is a substantial improvement in NNARX model over persistence results for all stations during severe geomagnetic conditions in February 1986. Table IV gives only RMS errors for NNARX model results in case of moderate and quiet geomagnetic conditions in September and December 1990. With the exception of the Sofia ionospheric station RMS errors, it is clear that the NNARX model results are as good as these in table III with a slight tendency of becoming worse during the more or less quiet geomagnetic activity in December 1990.

Encouraging results in tables III and IV of comparisons between actual and $1 \mathrm{~h}$ ahead

Table V. MAPE (\%) at different ionospheric stations for February 1986.

\begin{tabular}{cccccccc}
\hline \hline $\begin{array}{c}\text { Stations/NNARX model } \\
\text { input parameters }\end{array}$ & $\begin{array}{c}\text { RO041 } \\
\text { MAPE (\%) }\end{array}$ & $\begin{array}{c}\text { SQ143 } \\
\text { MAPE } \\
(\%)\end{array}$ & $\begin{array}{c}\text { PT046 } \\
\text { MAPE } \\
(\%)\end{array}$ & $\begin{array}{c}\text { SL051 } \\
\text { MAPE } \\
(\%)\end{array}$ & $\begin{array}{c}\text { JR055 } \\
\text { MAPE } \\
(\%)\end{array}$ & $\begin{array}{c}\text { MO155 } \\
\text { MAPE } \\
(\%)\end{array}$ & $\begin{array}{c}\text { UP158 } \\
\text { MAPE } \\
(\%)\end{array}$ \\
\hline$f o F 2$ only & 8.86 & 10.22 & 9.14 & $\mathbf{8 . 9 4}$ & 10.66 & $\mathbf{8 . 9 5}$ & $\mathbf{9 . 4 2}$ \\
$f o F 2+R_{i}+A_{p}$ & 8.71 & 10.07 & 8.63 & 9.10 & 10.79 & 9.88 & 10.25 \\
$f o F 2+R_{i}+D_{s t}$ & 8.93 & $\mathbf{9 . 8 6}$ & 8.89 & 9.18 & $\mathbf{1 0 . 1 9}$ & 9.59 & 10.29 \\
$f o F 2+R_{i}+A_{p}+D_{s t}$ & $\mathbf{8 . 7 0}$ & 9.90 & $\mathbf{8 . 6 0}$ & 9.26 & 10.46 & 9.97 & 11.03 \\
\hline
\end{tabular}

Table VI. MAPE (\%) at different European ionospheric stations for September 1990.

\begin{tabular}{cccccccc}
\hline \hline $\begin{array}{c}\text { Stations/NNARX model } \\
\text { input parameters }\end{array}$ & $\begin{array}{c}\text { RO041 } \\
\text { MAPE } \\
(\%)\end{array}$ & $\begin{array}{c}\text { SQ143 } \\
\text { MAPE } \\
(\%)\end{array}$ & $\begin{array}{c}\text { BE145 } \\
\text { MAPE } \\
(\%)\end{array}$ & $\begin{array}{c}\text { PT046 } \\
\text { MAPE } \\
(\%)\end{array}$ & $\begin{array}{c}\text { SL051 } \\
\text { MAPE } \\
(\%)\end{array}$ & $\begin{array}{c}\text { JR055 } \\
\text { MAPE } \\
(\%)\end{array}$ & $\begin{array}{c}\text { UP158 } \\
\text { MAPE } \\
(\%)\end{array}$ \\
\hline$f o F 2$ only & 4.16 & 8.85 & $\mathbf{4 . 9 7}$ & 4.26 & 4.62 & $\mathbf{4 . 5 2}$ & 6.20 \\
$f o F 2+R_{i}+A_{p}$ & $\mathbf{4 . 0 4}$ & 8.88 & 4.98 & $\mathbf{4 . 2 3}$ & 4.60 & 5.05 & 6.27 \\
$f o F 2+R_{i}+D_{s t}$ & 4.18 & 8.94 & 4.99 & 4.24 & $\mathbf{4 . 5 7}$ & 4.60 & $\mathbf{6 . 0 5}$ \\
$f o F 2+R_{i}+A_{p}+D_{s t}$ & 4.07 & $\mathbf{8 . 8 2}$ & 4.99 & 4.30 & $\mathbf{4 . 5 7}$ & 4.79 & 6.08 \\
\hline
\end{tabular}

Table VII. MAPE (\%) at different European ionospheric stations for December 1990.

\begin{tabular}{cccccccc}
\hline \hline $\begin{array}{c}\text { Stations/NNARX model } \\
\text { input parameters }\end{array}$ & $\begin{array}{c}\text { RO041 } \\
\text { MAPE } \\
(\%)\end{array}$ & $\begin{array}{c}\text { SQ143 } \\
\text { MAPE } \\
(\%)\end{array}$ & $\begin{array}{c}\text { PT046 } \\
\text { MAPE } \\
(\%)\end{array}$ & $\begin{array}{c}\text { BE145 } \\
\text { MAPE } \\
(\%)\end{array}$ & $\begin{array}{c}\text { SL051 } \\
\text { MAPE } \\
(\%)\end{array}$ & $\begin{array}{c}\text { JR055 } \\
\text { MAPE } \\
(\%)\end{array}$ & $\begin{array}{c}\text { UP158 } \\
\text { MAPE } \\
(\%)\end{array}$ \\
\hline$f o F 2$ only & $\mathbf{7 . 0 5}$ & 11.41 & 6.48 & 7.62 & 6.82 & 8.23 & 11.53 \\
$f o F 2+R_{i}+A_{p}$ & 7.22 & $\mathbf{1 1 . 2 7}$ & $\mathbf{6 . 2 3}$ & $\mathbf{7 . 3 4}$ & $\mathbf{6 . 6 3}$ & $\mathbf{8 . 6 0}$ & 10.26 \\
$f o F 2+R_{i}+D_{s t}$ & 7.13 & 11.65 & 6.32 & 7.40 & 6.82 & 8.81 & 10.61 \\
$f o F 2+R_{i}+A_{p}+D_{s t}$ & 6.73 & 12.40 & 6.54 & 8.53 & 6.72 & 8.62 & $\mathbf{9 . 0 3}$ \\
\hline
\end{tabular}


forecast foF 2 values show that there is a predictive advantage to neural network modelling which make it a useful tool to be introduced into the current ionospheric weather applications. For these purposes, it is shown here an interesting effect of different solar-terrestrial indices on $1 \mathrm{~h}$ ahead $f_{o} F 2$ forecasting by NNARX model. This time the prediction accuracy has been examined in terms of the Mean Absolute Percentage Error (MAPE) defined as

$$
\operatorname{MAPE}(\%)=\frac{1}{N} \sum_{i=1}^{N} \frac{\operatorname{abs}\left(x_{i}-y_{i}\right)}{x_{i}} \cdot 100 .
$$

A more in depth investigations of neural network forecasting of the key ionospheric characteristic foF 2 at different European ionospheric stations shown in tables V, VI and VII clearly demonstrate that $1 \mathrm{~h}$ ahead forecasting performances are not significantly improved by adding solar activity $R_{i}$ and/or geomagnetic $A_{p}$ and $D_{s t}$ indices as NNARX input parameters. It should be emphasised that these data and comparisons are specifically for a few stations but the results are applicable to the entire mid-latitude region at European longitudinal domain.

\section{Conclusions}

A neural network method has been developed for $1 \mathrm{~h}$ ahead forecasting of foF 2 . Comparisons with observations are very encouraging because of a very small errors and a high consistence between diurnal morphologies exhibited by forecasting method and observed trends. Furthermore, the effects of including various solar and geomagnetic indices as input parameters to the neural network were investigated, and it was found that performance was not improved by adding an index. Indeed, the NNARX model does not require neither predicted nor past values

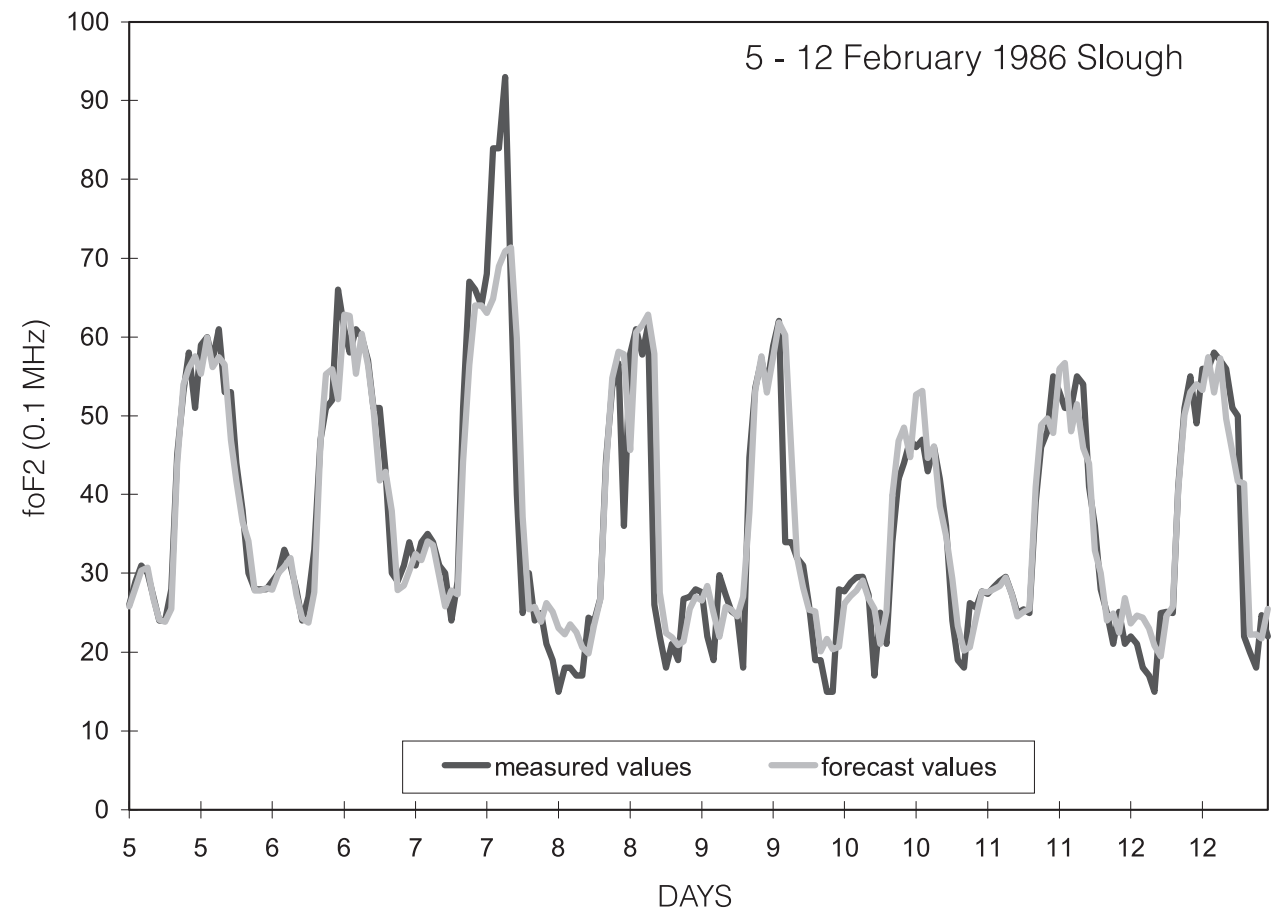

Fig. 1. Measured and NNARX model forecast $f o F 2$ values for a 8 day period in February 1986 at Slough ionospheric station. 
of solar and geomagnetic indices to forecast $1 \mathrm{~h}$ ahead $f o F 2$ values even during geomagnetically very disturbed periods as those in February 1986 (see fig. 1). It remains to be seen to what extent the artificial neural network performance, such as the NNARX model, can be improved in predicting foF 2 values up to $24-\mathrm{h}$ ahead. NNARX model is implemented in MATLAB 5.2.1 and requires its installation on PC Pentium II platform. It has MATLAB type of friendliness with low level of interaction and requires training data for $f o F 2$ for recent 365 days.

This work could be extended to space weather forecasting with the application of predicting disturbance effects. This will clearly involve prediction techniques based on the access and manipulation of real time ionospheric data.

\section{REFERENCES}

Altinay, O., E. Tulunay and Y. Tulunay (1997): Forecasting of ionospheric frequency using neural networks, Geophys. Res. Let., 24, 1467-1470.

AKAIKE, H. (1969): Fitting autoregressive models for prediction, Ann. Inst. Stat. Mat., 21, 243-247.

Bishop, C.M. (2000): Neural Networks for Pattern Recognition (Oxford University Press, Oxford), pp. 504.

CANDER, LJ.R. (1998): Space weather effects on telecommunication, in AI Applications in Solar-Terrestrial Physics, edited by I. SANDAHL and E. JONSSON, ESA WPP-148 Proceedings, 35-42.

CANDER, LJ.R. (2003): Toward forecasting and mapping ionospheric space weather under the COST actions, Adv. Space Res., 31 (4), 957-964.

CAnder, Lu.R., S. Stankovic and M. MilosavlueviC (1998a): Dynamic ionospheric prediction by neural networks, in AI Applications in Solar-Terrestrial Physics, edited by I. SANDAHL and E. JONSSON, ESA WPP-148 Proceedings, 225-228.

CAnder, LJ.R., M.M. Milosavljevic, S.S. StankoviC and S. TOMASEVIĆ (1998b): Ionospheric forecasting technique by artificial neural network, Electron. Lett., 34 (16), 1573-1574.

Francis, N.M., A.G. Brown and P.S. CANNON (2001): Predictionn of the hourly ionospheric parameter $f_{o} F 2$ using a novel nonlinear interpolation technique to cope with missing data points, J. Geophys. Res. Space Phys., 106 (A12), 30,415-30,428.

Fuller-Rowell, T., E. Araujo-Pradere and M. CONDRESCU (2000): An empirical ionospheric stort-time correction model, Adv. Space Res., 25 (1), 138-148.

LAMMING, X. and LJ.R. CANDER (1998): Monthly median ionospheric frequencies model using neural networks, in AI Applications in Solar-Terrestrial Physics, edited by I. SANDAHL and E. JONSSON, ESA WPP-148 Proceedings, 229-234.

LAMMING, X. and LJ. R. CANDER (1999): Monthly median foF 2 modelling COST 251 area by neural networks, Phys. Chem. Earth (C), 24 (4), 349-354.

LE Cun, Y., J.S. DenKer and S.A. Solla (1990): Optimal brain demage, in Advances in Neural Information Processing Systems, edited by M. KAUFMAN, vol. 2, 598-605

Muhtarov, P., I. Kutiev, LJ.R. CANDER, B. Zolesi, G. DE FRANCESCHI, M.F. LEVY and M. DICK (2001): European ionospheric forecasting and mapping, Phys. Chem. Earth (C), 26 (5), 347-351.

Muhtarov, P., I. Kutiev and LJ.R. CANDER (2002): Geomagnetically correlated autoregression model for short-term prediction of ionospheric parameters, Inverse Problems, 18, 49-65.

Kutiev, I., P. Muhtarov, LJ. R. CANDER and M.F. LeVy (1999): Short-term prediction of ionospheric parameters based on auto-correlation analysis, Ann. Geofis., 42 (1), 121-127.

WilliscrofT, L.-A. and A.W.A. Poole (1996): Neural networks, $f_{o} F 2$, sunspot number and magnetic activity, Geophys. Res. Lett., 23, 3659-3662.

WinTOFT, P. and LJ.R. CANDER (2000a): Twenty-four hour predictions of $f_{O F} 2$ using time delay neural networks, Radio Sci., 35 (2), 395-408.

WINTOFT, P. and LJ.R. CANDER (2000b): Ionospheric foF2 storm forecasting using neural networks, Phys. Chem. Earth (C), 25 (4), 267-273.

(received May 2, 2003; accepted July 10, 2003) 